\title{
Bolus Fluorouracil/Leucovorin Regimen
}

National Cancer Institute

\section{Source}

National Cancer Institute. Bolus Fluorouracil/Leucovorin Regimen. NCI Thesaurus. Code C136254.

A chemotherapy regimen consisting of bolus fluorouracil and leucovorin that is used for the treatment of colon cancer. 